\title{
Fibrose cística no adulto: aspectos diagnósticos e terapêuticos*
}

\author{
Cystic fibrosis in adults: diagnostic and therapeutic aspects
}

\author{
Paulo de Tarso Roth Dalcin', Fernando Antônio de Abreu e Silva²
}

\begin{abstract}
Resumo
A fibrose cística, que já foi considerada uma doença da infância, é agora também uma doença do adulto. 0 aumento da longevidade resultou em mais problemas médicos relacionados com a idade e com a própria doença. 0 crescente número de adultos com fibrose cística resultou em aumento da necessidade de cuidados médicos. Essa necessidade tem sido suprida por um crescente número de pneumologistas de adultos e outros especialistas. 0 objetivo dessa revisão é sumarizar o conhecimento corrente sobre o diagnóstico e tratamento no adulto com fibrose cística. Na maioria dos casos, o diagnóstico é sugerido por manifestações de doença sinopulmonar crônica e insuficiência pancreática exócrina, e, então, confirmado por um teste do suor positivo. Pacientes adultos podem, entretanto, apresentar suficiência pancreática e características clínicas atípicas, às vezes, associadas com teste do suor normal ou limítrofe. Em tais casos, a possibilidade de realizar pesquisa de mutações para fibrose cística e de medir a diferença de potencial nasal pode ser de utilidade diagnóstica. A abordagem terapêutica padrão para a doença pulmonar inclui: antibióticos, higiene das vias aéreas, exercício, mucolíticos, broncodilatadores, oxigênio, agentes anti-inflamatórios e suporte nutricional. A utilização adequada dessas terapias resulta em mais pacientes com fibrose cística sobrevivendo na vida adulta com uma aceitável qualidade de vida.
\end{abstract}

Descritores: Fibrose cística; Diagnóstico; Terapêutica; Mucoviscidose.

\begin{abstract}
Once considered a childhood disease, cystic fibrosis is now also a disease of adults. Increased longevity has resulted in the aging of the cystic fibrosis population. The consequent age-related medical problems among adults with cystic fibrosis have increased medical care needs. These needs are being met by a growing number of non-pediatric pulmonologists and other non-pediatric specialists. The objective of this review was to summarize the current knowledge about diagnosis and treatment in adult cystic fibrosis. In most cases, the diagnosis is suggested by manifestations of chronic sinopulmonary disease and exocrine pancreatic insufficiency. The diagnosis is confirmed by a positive sweat test result. Adult patients may, however, present pancreatic sufficiency and atypical clinical features, sometimes in combination with normal or borderline sweat test results. In such cases, identifying cystic fibrosis mutations and measuring nasal potential difference can have diagnostic utility. The standard therapeutic approach to pulmonary disease includes the use of antibiotics, airway clearance, exercise, mucolytics, bronchodilators, oxygen therapy, anti-inflammatory agents and nutritional support. Appropriate application of these therapies results in most cystic fibrosis patients surviving into adulthood with an acceptable quality of life.
\end{abstract}

Keywords: Cystic fibrosis; Diagnosis; Therapeutics; Mucoviscidosis.

\footnotetext{
* Trabalho realizado na Faculdade de Medicina da Universidade Federal do Rio Grande do Sul e no Hospital de Clínicas de Porto Alegre, Porto Alegre (RS) Brasil. 1. Professor Adjunto do Departamento de Medicina Interna da Universidade Federal do Rio Grande do Sul - UFRGS - Porto Alegre (RS) Brasil.

2. Professor Adjunto do Departamento de Pediatria e Puericultura da Universidade Federal do Rio Grande do Sul - UFRGS - Porto Alegre (RS) Brasil.

Endereço para correspondência: Paulo de Tarso Roth Dalcin. Rua Honório Silveira Dias, 1529/901, Bairro São João, CEP 90540-070, Porto Alegre, RS, Brasil.

Tel 5551 3330-0521. E-mail: pdalcin@terra.com.br

Recebido para publicação em 29/7/2007. Aprovado, após revisão, em 28/8/2007.
} 


\section{Introdução}

A fibrose cística (FC) é uma doença genética cujo padrão de hereditariedade é autossômico recessivo. É causada por mutações em um gene localizado no braço longo do cromossoma 7. ${ }^{(1)}$ Esse gene é responsável pela codificação de uma proteína com 1.480 aminoácidos denominada regulador da condutância transmembrana da FC, conhecido em inglês como cystic fibrosis transmembrane condutance regulator (CFTR). ${ }^{(2,3)}$ Essa proteína se constitui em um canal de cloretos na membrana apical das células epiteliais exócrinas, regulando e participando do transporte de eletrólitos através das membranas celulares. ${ }^{(4)} \mathrm{A}$ expressão clínica da doença é muito variada. Em geral, apresenta-se como um envolvimento multissistêmico, caracterizado por doença pulmonar progressiva, disfunção pancreática exócrina, doença hepática, problemas na motilidade intestinal, infertilidade masculina (azoospermia obstrutiva) e concentrações elevadas de eletrólitos no suor. ${ }^{(5,6)}$

A doença, descrita por Andersen ${ }^{(7)}$ em 1938 como 'fibrose cística do pâncreas', tinha até menos de 70 anos atrás um prognóstico quase que uniformemente fatal no primeiro ano de vida. Ao longo dos anos, o avanço no conhecimento sobre a fisiopatologia e nas formas de tratamento tornou cada vez maior a sobrevivência desses pacientes. Dados do registro norte-americano mostram que a idade mediana de sobrevida é, atualmente 36,5 anos, e que $43 \%$ das pessoas com FC têm mais que 18 anos. ${ }^{(8)}$

0 aumento da longevidade na FC resultou em uma maior proporção de problemas médicos relacionados com a idade e com a progressão da doença, modificando as necessidades na assistência da saúde. Exigiu, sobretudo, que profissionais de diferentes especialidades na área de saúde do adulto se envolvessem no atendimento desses pacientes. Como a doença pulmonar é progressiva e constitui-se no principal determinante prognóstico da doença, cabe ao pneumologista de adultos importante papel no atendimento multidisciplinar a esses pacientes. ${ }^{(8)}$

0 objetivo deste artigo é revisar os principais aspectos diagnósticos e terapêuticos na FC do adulto.

\section{Diagnóstico}

A Tabela 1 apresenta os critérios diagnósticos de FC. A FC é diagnosticada pela presença de pelo
Tabela 1 - Critérios diagnósticos de fibrose cística.

\begin{tabular}{|c|c|}
\hline Achados de fibrose cística & $\begin{array}{l}\text { Evidência laboratorial } \\
\text { de disfunção da CFTR }\end{array}$ \\
\hline$\geq 1$ achado fenotípico & Teste do suor positivo \\
\hline ou & $\mathrm{ou}$ \\
\hline Triagem neonatal positiva mais & DPN positiva \\
\hline ou & ou \\
\hline História familiar positiva & 2 mutações ${ }^{\mathrm{a}}$ na CFTR \\
\hline \multicolumn{2}{|c|}{$\begin{array}{l}\text { CFTR: regulador da condutância transmembrana da fibrose } \\
\text { cística; e DPN: diferença de potencial nasal. a As mutações na } \\
\text { CFTR devem ser conhecidas como causadoras de FC. Adaptada } \\
\text { de Rosenstein \& } \text { Cutting }^{(9)} \text {. }\end{array}$} \\
\hline
\end{tabular}

menos um achado fenotípico (Quadro 1), história familiar de FC ou triagem neonatal positiva, acompanhada de evidência laboratorial de disfunção da CFTR - teste do suor positivo ou diferença de potencial nasal (DPN) positivo - ou pela identificação de duas mutações conhecidas como causa de FC nos genes da CFTR). ${ }^{(5,9)}$

\section{Teste do suor}

0 teste do suor através da iontoforese quantitativa pela pilocarpina é o padrão-áureo para a confirmação do diagnóstico de $\mathrm{FC} .{ }^{(5,9,10)}$ Os métodos de coleta são o procedimento de Gibson-Cooke e o sistema de coleta de suor Macroduct (Wescor, Logan, UT, USA). Em ambos, o suor é estimulado pela iontoforese pela pilocarpina e coletado em papel filtro ou gaze (Gibson-Cooke) ou em tubo microbore (Wescor). A amostra é, então, analisada para concentração de cloreto e sódio. 0 volume de suor mínimo aceitável é de $75 \mathrm{mg}$ no procedimento de Gibson-Cooke e de $15 \mu \mathrm{L}$ para o sistema Macroduct. ${ }^{(5,9)}$

Outros métodos, como a medida de condutividade (medida não-seletiva de íons) e a medida da osmolaridade, podem ser utilizados como teste de triagem. Nesse caso, valores alterados ou equívocos devem ser confirmados por um teste quantitativo do suor. ${ }^{(5,9)}$

0 teste do suor deve ser sempre interpretado em face do contexto clínico. 0 cloreto fornece a melhor discriminação diagnóstica. A medida do sódio é útil para controle de qualidade. Valores muito discordantes indicam problemas na coleta ou análise. Uma concentração de cloreto maior que $60 \mathrm{mmol} / \mathrm{L}$ é consistente com o diagnóstico de FC. Os valores 
Quadro 1 - Achados fenotípicos consistentes com o diagnóstico de fibrose cística.

1. Doença sinopulmonar crônica manifesta por:

a) Colonização/infecção persistente com patógenos típicos de fibrose cística, incluindo Staphylococcus aureus, Haemophilus influenza não-tipável, Pseudomonas aeruginosa mucóide e não-mucóide, e Burkholderia cepacia.

b) Tosse e expectoração crônicas.

c) Anormalidades persistentes no exame radiológico do tórax (bronquiectasias, atelectasias, infiltrados e hiperinsuflação).

d) Obstrução das vias aéreas com sibilância e alçaponamento aéreo.

e) Pólipos nasais, anormalidades radiográficas ou tomográficas dos seios paranasais.

f) Baqueteamento digital.

2. Anormalidades gastrointestinais e nutricionais, incluindo:

a) Intestinal: íleo meconial, síndrome da obstrução intestinal distal e prolapso retal.

b) Pancreática: insuficiência pancreática e pancreatite recorrente.

c) Hepática: doença hepática crônica manifesta por evidências clínicas ou histológicas de cirrose biliar focal ou cirrose multilobular.

d) Nutricional: prejuízo de desenvolvimento (desnutrição proteico-calórica), hipoproteinemia e edema, complicações secundárias à deficiência de vitaminas lipossolúveis.

3. Síndromes perdedoras de sal: depleção aguda de sal e alcalose metabólica crônica.

4. Anormalidades urogenitais masculinas resultando em azoospermia obstrutiva (ausência congênita bilateral dos ductos deferentes).

Adaptado de Rosenstein \& Cutting ${ }^{(9)}$.

de cloretos entre 40 e $60 \mathrm{mmol} / \mathrm{L}$ são considerados limitrofes. ${ }^{(5,9)}$

Todo o teste do suor deve ser realizado pelo menos duas vezes em cada paciente, preferentemente com intervalo de semanas entre eles. Todo o teste do suor positivo deve ser repetido ou confirmado por análise de mutações. 0 teste do suor com valor limítrofe deve ser repetido. Se o resultado continuar indeterminado, testes diagnósticos adicionais deverão ser realizados. ${ }^{(5)}$

\section{Análise de mutações}

A identificação de mutações conhecidas como causa de FC em cada um dos genes da CFTR, frente a um contexto clínico ou história familiar compatível, estabelece o diagnóstico de FC. Entretanto, o achado de uma ou de nenhuma mutação no gene da CFTR não exclui o diagnóstico de FC. ${ }^{(9)}$ Além disso, já foram relatados pacientes com FC não-clássica sem evidência de mutações nos genes da CFTR. ${ }^{(11-13)}$ Portanto, a existência de genótipos complexos, de fatores modificadores e de mutações atenuadoras exigem que o diagnóstico de FC seja feito com a contribuição dos achados clínicos. ${ }^{(14)}$
A análise de mutações para confirmar o diagnóstico de FC tem alta especificidade, porém baixa sensibilidade..$^{(9)}$ A baixa sensibilidade decorre da existência de um grande número de mutações conhecidas como causa de FC (mais de 1.000) e do fato de que os painéis comerciais disponíveis para essa análise só estudam uma minoria dessa mutações. ${ }^{(8)}$ Poucos centros de referência podem disponibilizar painéis com maior número de mutações ou realizar o seqüenciamento genético para o diagnóstico dos casos mais atípicos. ${ }^{(10)}$

\section{Diferença de potencial nasal}

As anormalidades do transporte iônico no epitélio respiratório na FC estão associadas com um padrão alterado na DPN. Especificamente, três características distinguem a FC: a) uma DPN basal mais elevada; b) uma maior inibição da DPN, após a perfusão nasal com amilorida; c) pouca ou nenhuma alteração na DPN, após a perfusão do epitélio nasal com uma solução livre de $\mathrm{Cl}^{-}$em conjunção com isoproterenol. ${ }^{(9)}$

Uma DPN aumentada, em associação com quadro clínico ou história familiar positiva, fundamenta o diagnóstico de FC. Entretanto, a ausência 
de aumento na DPN não exclui o diagnóstico de FC, pois um resultado falso-negativo pode ocorrer na presença do epitélio inflamado. É recomendado que a DPN seja avaliada pelo menos duas vezes em momentos diferentes. ${ }^{(9)}$ Entretanto, essa técnica só está disponível em centros altamente especializados e requer uma padronização rigorosa. ${ }^{(8)}$

\section{Exames complementares}

$\mathrm{Na}$ avaliação diagnóstica inicial, outros exames complementares são utilizados. Eles contribuem de forma secundária para o diagnóstico, para avaliar a gravidade da doença e para planejar abordagens terapêuticas específicas. Incluem a avaliação da função pancreática, avaliação funcional pulmonar, avaliação microbiológica do escarro, avaliação dos seios da face e avaliação gênito-urinária masculina (azoospermia obstrutiva). ${ }^{(10)}$

\section{$O$ paciente adulto}

Embora o diagnóstico de FC seja usualmente feito na infância $(70 \%$ dos casos no primeiro ano de vida), a freqüência do diagnóstico na vida adulta tem aumentado. ${ }^{(8)}$

Em geral, os pacientes diagnosticados na vida adulta possuem formas não-clássicas de FC. Eles se apresentam com doença respiratória crônica, porém de menor gravidade, com menor freqüência de infecção por Pseudomonas aeruginosa e com menor freqüência de insuficiência pancreática do que os pacientes com FC diagnosticados na infância. Além disso, um outro fator que contribui para a dificuldade diagnóstica é que uma considerável parcela desses pacientes apresenta teste do suor normal ou limitrofe. ${ }^{(15-17)}$

No Brasil, Lemos et al. ${ }^{(18)}$ descrevem 28 pacientes com diagnóstico de FC na vida adulta no estado da Bahia. A média de idade foi de 31, 1 anos, 53,7\% eram negros ou mulatos e 43\% tinha $P$. aeruginosa na cultura do escarro. Reforçam a importância de investigar FC em pacientes adultos com infecção respiratória de repetição, sinusite e bronquiectasias. Paschoal et al. ${ }^{(19)}$ descreveram 54 pacientes com diagnóstico de FC na vida adulta em Campinas (São Paulo). A média de idade foi de 41,8 anos, 85\% tinha tosse produtiva crônica, $6 \%$ tinha diarréia ou fezes gordurosas, $48 \%$ tinha $P$. aeruginosa na cultura do escarro e o volume expiratório forçado no primeiro segundo $\left(\mathrm{VEF}_{1}\right)$ foi de $52 \%$.
A despeito dessas diferenças, os critérios diagnósticos para $\mathrm{FC}$ são os mesmos tanto para crianças como para adultos ${ }^{(9)}$ Além da repetição do teste do suor, em geral o diagnóstico exige a realização de uma análise de mutações mais abrangente. A DPN pode ser útil, mas a dificuldade de padronização do teste é um fator limitante na prática clínica. ${ }^{(15)} \mathrm{Na}$ ausência de sintomas gastrointestinais, o diagnóstico diferencial deve incluir discinesia ciliar, deficiência de imunoglobulina G e síndrome de Young. ${ }^{(5)}$

\section{Tratamento}

A FC é uma doença complexa que exige uma abordagem holística para o seu tratamento. A utilização do modelo de abordagem multidisciplinar para tratar a doença se fundamenta na observação de que a formação de centros abrangentes de cuidados em FC está relacionada com o progressivo melhor prognóstico dos pacientes. ${ }^{(8,20)}$ Assim, as recomendações para os centros de adultos seguem o modelo multidisciplinar bem sucedido dos centros pediátricos. ${ }^{(8)}$

A despeito do grande avanço sobre o conhecimento da FC, o tratamento da doença é baseado no tratamento sintomático e na correção das disfunções orgânicas. ${ }^{(21,22)}$

A FC é uma doença multissistêmica, mas o envolvimento pulmonar é a causa principal de morbidade e mortalidade. ${ }^{(23)}$ Embora o curso da doença pulmonar seja invariavelmente de deterioração progressiva, a abordagem terapêutica adequada pode retardar a progressão da doença pulmonar. ${ }^{(23,24)}$

0 regime terapêutico padrão para a doença pulmonar inclui: a) antibioticoterapia, b) higiene das vias aéreas e exercício, c) agentes mucolíticos, d) broncodilatadores, e) agentes antiinflamatórios, f) suporte nutricional e g) suplementação de oxigênio. ${ }^{(8,23-25)}$

\section{Antibioticoterapia}

Os antibióticos são a pedra fundamental do tratamento da doença pulmonar na FC. Os pacientes com FC devem ser avaliados rotineiramente, idealmente a cada quatro meses, quanto à microbiologia e antibiograma do escarro. ${ }^{(8)}$

Os antibióticos podem ser utilizados em quatro situações clínicas específicas na FC: a) no tratamento das exacerbações infecciosas, b) na erradicação ou tratamento em longo prazo para o Staphylococcus 
aureus, c) na erradicação precoce da infecção por $P$. aeruginosa e d) no tratamento supressivo da infecção crônica por P. aeruginosa. ${ }^{(26)}$

Os pacientes com FC podem apresentar agravamentos periódicos na intensidade de seus sintomas respiratórios relacionados com infecções respiratórias, com exposição a poluentes atmosféricos ou com hiperreatividade das vias aéreas. ${ }^{(27)} 0$ tratamento intermitente das exacerbações pode ser feito com antibióticos por via oral ou por via intravenosa, dependendo da gravidade do quadro clínico.(26) Para os pacientes com exacerbações mais graves, é preconizado o tratamento com antibióticos por via intravenosa por 14 a 21 dias, em geral exigindo hospitalização. ${ }^{(25)}$ A escolha dos antibióticos é baseada na revisão das culturas de escarro e antibiogramas mais recentes. ${ }^{(21,24)} 0$ alvo do tratamento antibiótico abrange os patógenos especificamente relacionados com a $\mathrm{FC}$, como a $P$. aeruginosa, o S. aureus e a $B$. cepacia. ${ }^{(23)}$ Como a $P$. aeruginosa é o patógeno mais freqüentemente isolado em adultos com $\mathrm{FC},{ }^{(8,28)}$ geralmente se utiliza o tratamento com fluoroquinolonas para as exacerbações leves, enquanto a combinação de uma droga beta-lactâmica com um aminoglicosídeo está indicada para o tratamento das exacerbações mais graves. ${ }^{(8)}$

Geralmente, o $S$. aureus é a primeira bactéria cultivada na secreção respiratória em crianças com FC, permanecendo como um importante patógeno no adulto. ${ }^{(29)}$ As abordagens para o tratamento do S. aureus incluem, além do curso antibiótico na exacerbação, um curso curto de antibiótico frente à identificação da cultura de escarro positiva e antibioticoterapia prolongada a partir do diagnóstico. ${ }^{(22,29)}$ Muitos centros recomendam a erradicação precoce dessa bactéria, utilizando curso de antibiótico por duas a quatro semanas, mesmo na ausência de sintomas. ${ }^{(22)}$ Embora o sucesso da erradicação seja de 75\%, ocorre recidiva da infecção após a cessação do antibiótico. ${ }^{\left({ }^{(30)}\right.} \mathrm{A}$ antibioticoterapia contínua com flucloxacilina, iniciada a partir do diagnóstico, resultou em menores taxas de culturas de $S$. aureus, menos tosse e menores taxas de internação. ${ }^{(31)}$ Entretanto, o tratamento anti-estafilocócico contínuo resultou em taxas de aquisição de $P$. aeruginosa mais elevadas. ${ }^{(32)}$ No estado atual, não existem evidências suficientes para definir a utilização da antibioticoterapia profilática para o S. aureus. ${ }^{(33)}$
A aquisição e a persistência da $P$. aeruginosa no trato respiratório inferior de pacientes com FC estão associadas com maior morbidade e mortalidade. ${ }^{(34)}$ Inicialmente, as cepas isoladas têm a aparência nãomucóide e são multissensíveis aos antibióticos. ${ }^{(35)}$ Essas cepas de infecção recente podem ser erradicadas através de tratamento antibiótico agressivo. Entretanto, com o tempo, desenvolvem-se cepas de $P$. aeruginosa com fenótipo mucóide que se associam com declínio mais acelerado na função pulmonar e maior risco de morte. A infecção crônica da $P$. aeruginosa de fenótipo mucóide é usualmente impossível de erradicar e a meta do tratamento antibiótico passa a ser, então, a supressão do patógeno. ${ }^{(36)}$ Assim, frente à identificação inicial da $P$. aeruginosa, o tratamento precoce e agressivo para tentar a erradicação e prevenir a infecção crônica tem sido recomendado. Entretanto, uma área de incerteza no manejo da erradicação precoce da $P$. aeruginosa é qual o melhor regime terapêutico e qual a sua duração. Uma alternativa prática para essa abordagem consiste na combinação da ciprofloxacina oral com o colistin inalatório por um período de três a seis semanas. Naqueles pacientes com recidiva ou naqueles com identificação inicial de cepas mucóides, é sugerido um curso mais prolongado de três meses. ${ }^{(37)}$ A utilização da tobramicina inalatória por 28 dias também obteve uma significante taxa de erradicação. ${ }^{(38)} A$ erradicação também foi demonstrada com a combinação de antibióticos por via intravenosa com antibióticos inalatórios, porém com desvantagens econômicas e logísticas. ${ }^{(37)}$

0 uso inalatório de antibióticos tem sido empregado como forma de tratamento supressivo da infecção crônica pela $P$. aeruginosa, com evidências de melhora nos desfechos funcionais e curso clínico. ${ }^{(39)}$ Estudos iniciais utilizaram os aminoglicosídeos, em especial a tobramicina, nas doses de 60-80 mg, nebulizadas duas a três vezes ao dia. 0 colistin (Polimixina E) tem sido largamente utilizado na Europa nas dose de 500.000-1.000.000 Ul, nebulizado duas vezes ao dia. Uma preparação de tobramicina inalatória livre de fenol, administrada nas doses de $300 \mathrm{mg}$ duas vezes ao dia, por 28 dias com intervalo livre de 28 dias, tem sido a forma de tratamento melhor estudada por ensaios clínicos. A despeito desses avanços, ainda faltam evidências para definir qual a melhor droga para a supressão crônica. ${ }^{(26)}$ 
As evidências para o uso oral crônico de antibióticos em adultos com $\mathrm{FC}$ são muito precárias e não recomendadas. ${ }^{(8)}$ Entretanto, tem sido demonstrado que o tratamento oral com macrolídeo melhora a função pulmonar e diminui a freqüência de exacerbações em pacientes com $P$. aeruginosa. Os principais efeitos adversos demonstrados são náuseas e diarréia. Também, hepatotoxicidade e ototoxicidade têm sido evidenciadas. Os macrolídeos parecem exercer seus efeitos através de ação sobre a bactéria patogênica (afeta a formação do biofilme da $P$. aeruginosa) e sobre o hospedeiro (efeitos imunomodulatórios). 0 benefício do uso prolongado da azitromicina parece se estender também aos pacientes sem infecção pela $P$. aeruginosa. Existe uma grande heterogeneidade na resposta à azitromicina. As doses utilizadas de azitromicina foram 250 a $500 \mathrm{mg}$ ao dia e $250 \mathrm{mg}$ (peso $<40 \mathrm{~kg}$ ) a $500 \mathrm{mg}$ três vezes por semana. ${ }^{(40)}$

\section{Higiene das vias aéreas e exercício}

As medidas mecânicas para aumentar o clearance mucociliar têm se constituído em um dos pilares fundamentais no tratamento da FC. ${ }^{(24)}$ Existe uma variedade de técnicas fisioterápicas para a higiene das vias aéreas. ${ }^{(23)}$ As técnicas convencionais incluem drenagem postural e percussão torácica em posições anatômicas diferentes, de forma a facilitar por ação da gravidade a remoção de secreções. A despeito das evidências de benefícios com essas técnicas, elas podem acarretar hipóxia, particularmente em pacientes com doenças graves, e refluxo gastroesofágico. Além disso, essas técnicas exigem assistência para sua realização, consumindo tempo e tornando o paciente dependente de seus cuidadores, resultando em baixa adesão. À medida que o paciente se torna adulto, a autonomia passa a ser uma prioridade. Mais recentemente, foram desenvolvidas técnicas fisioterápicas que permitem a higiene das vias aérea sem assistência. Esses métodos incluem: drenagem autogênica, drenagem autogênica modificada, ciclo ativo da respiração, técnica de expiração forçada, pressão expiratória positiva aplicada por máscara, técnicas com dispositivos oscilatórios orais, compressões torácicas de alta freqüência e ventilação percussiva intrapulmonar. 0 paciente deve ser orientado na escolha, na realização correta das manobras e na melhor combinação de técnicas. A freqüência e a duração do tratamento devem ser individualizadas. Pacientes com sintomas respirató- rios mínimos podem necessitar apenas uma sessão de fisioterapia por dia, enquanto pacientes com doença pulmonar mais grave ou com grande quantidade de secreção podem necessitar três ou mais sessões por dia. ${ }^{(24)}$

A atividade física aumenta o clearance das vias aéreas e se constitui em um importante adjuvante nas medidas de higiene brônquica. 0 exercício atenua o declínio da função pulmonar, melhora o desempenho cardiovascular, aumenta a capacidade funcional e melhora a qualidade de vida. Por essas razões, o exercício deve ser recomendado aos pacientes adultos com $\mathrm{FC}^{\left({ }^{(8)}\right.}$ Pacientes com doença pulmonar mais grave devem ser avaliados quanto à necessidade de receber suplementação de oxigênio durante a atividade física. ${ }^{(4)}$ Regimes de reabilitação pulmonar mostraram benefício em pacientes com FC. ${ }^{(8)}$

\section{Agentes mucolíticos}

A viscosidade anormal do escarro na FC é causada pelo DNA extra-celular liberado pelos neutrófilos. A preparação de DNase humana recombinante ou alfadornase, administrada pela via inalatória, diminui a viscosidade do escarro na FC através da degradação do DNA extra-celular em pequenos fragmentos. Foi demonstrado benefício da alfa-dornase em pacientes com mais de 5 anos de idade e com $\mathrm{VEF}_{1}$ maior que $40 \%$ do previsto, com redução na taxa de exacerbação da doença pulmonar de $22 \%$ e melhora no $\mathrm{VEF}_{1}$ de 5,8\%. Em pacientes com doença pulmonar mais grave $\left(\mathrm{VEF}_{1}<40 \%\right.$ do previsto), foi observado benefício funcional pulmonar, mas não redução nas exacerbações. A dose recomendada da alfa-dornase é de $2,5 \mathrm{mg}$, nebulizada uma vez ao dia. Os principais efeitos adversos são rouquidão, alteração da voz e faringite. Na maioria dos casos, esses sintomas são auto-limitados. ${ }^{(24)}$

A nebulização de solução salina hipertônica aumenta o transporte ciliar, melhora as propriedades reológicas do escarro e melhora a hidratação da superfície das vias aéreas. A nebulização com solução salina de 3 a 7\% na FC melhora o clearance mucociliar e a função pulmonar em curto período de tempo. ${ }^{(42)}$ Mais recentemente, um ensaio clínico estudou a nebulização de $4 \mathrm{~mL}$ de solução salina hipertônica a 7\%, durante um período de 48 semanas, mostrando significativa melhora funcional pulmonar e redução de 56\% nas taxas de exacerbação e não se 
associando com piora na infecção bacteriana ou na inflamação. Assim, a nebulização de solução salina hipertônica, precedida pela inalação de um broncodilatador, é uma medida terapêutica barata e segura na FC, cujos benefícios terapêuticos parecem ser independentes do uso da alfa-dornase. ${ }^{(43)}$

Embora a $\mathrm{N}$-acetilcisteína, na forma nebulizada, tenha sido usada na FC para reduzir a viscosidade do escarro, sua utilização carece de evidências suficientes. Além disso, essa droga pode ser irritante para as vias aéreas e causar broncoconstrição. Também a forma oral da medicação não possui fundamentação para sua utilização. ${ }^{(23,24)}$

\section{Broncodilatadores}

A hiper-reatividade brônquica é muito freqüente na $\mathrm{FC}$, ocorrendo em cerca da metade dos pacientes. Assim, os broncodilatadores inalatórios têm sido utilizados como parte do tratamento padrão da $\mathrm{FC} .{ }^{(24)}$ Os agentes mais freqüentemente empregados são os agonistas beta -adrenérgicos de curta ação. São utilizados geralmente antes da fisioterapia respiratória para facilitar o clearance das vias aéreas. ${ }^{\left({ }^{8}\right)} \mathrm{A}$ maioria dos pacientes apresenta melhora funcional com sua utilização. 0 emprego do brometo de ipratrópio como broncodilatador na FC tem dados limitados e controversos, porém a maioria dos estudos mostra um modesto benefício funcional. Assim, todos pacientes com FC devem ser avaliados quanto à hiper-reatividade brônquica e um teste terapêutico com medicações broncodilatadoras deve ser realizado. ${ }^{(23)}$

\section{Agentes antiinflamatórios}

A busca de uma estratégia antiinflamatória que detenha a progressão do processo fisiopatológico na FC tem sido alvo de inúmeras pesquisas. Apesar de todos os esforços, ainda não foi identificada uma droga que seja eficaz e segura para esse fim. ${ }^{(44)}$

Os corticosteróides orais na dose de 1 a $2 \mathrm{mg} / \mathrm{kg}$ em dias alternados parece retardar a progressão da doença pulmonar, mas os benefícios são contrabalançados pela ocorrência de importantes efeitos adversos, especialmente desenvolvimento de catarata e prejuizo no crescimento. Faltam evidências para o uso dos corticosteróides sistêmicos nas exacerbações. Entretanto, os corticosteróides sistêmicos têm sido utilizados como recurso terapêutico em pacientes com exacerbações graves, especialmente na presença de hiper-reatividade brônquica. ${ }^{(23)}$

Os corticosteróides inalatórios também têm sido estudados na FC com o objetivo de reduzir o processo inflamatório e diminuir a lesão pulmonar. Entretanto, no estado atual, as evidências são insuficientes para estabelecer se há benefício no seu uso. ${ }^{(45)}$

Doses elevadas de ibuprofeno (20 a $30 \mathrm{mg} / \mathrm{kg}$ ao dia) foram estudadas em pacientes com FC, evidenciando redução na taxa de declínio do $\mathrm{VEF}_{1}$, redução nas hospitalizações e melhora no estado nutricional. Entretanto, a incidência de insuficiência renal e de hemorragia gastrointestinal duplicou, limitando a sua utilização. Também existe a necessidade de monitorizar o nível sérico da medicação. Uma revisão demonstrou a falta de evidências para recomendar o uso do ibuprofeno na rotina clínica. ${ }^{(46)}$

Outros antiinflamatórios são bem menos estudados na FC. 0 montelucaste reduz a inflamação eosinofílica na FC, mas as evidências clínicas sobre o assunto são precárias. ${ }^{(44)}$

\section{Suporte nutricional}

0 estado nutricional desempenha um importante papel no curso clínico da FC. Prejuízos no estado nutricional acarretam alterações na função pulmonar e interferem na sobrevida do paciente. A intervenção nutricional deve ser precoce, evitando deterioração na função pulmonar e afetando positivamente a sobrevida. Todo o paciente com FC deve ser avaliado regularmente a fim de monitorizar o estado nutricional e assegurar uma adequada ingestão calórica. ${ }^{(20)} \mathrm{A}$ recomendação inclui uma dieta rica em gordura, com 35 a 40\% das calorias a partir dessa fonte..$^{(8)} 0$ paciente com FC pode necessitar 120 a 150\% das necessidades diárias estimadas. Uma estimativa aproximada das necessidades energéticas pode ser feita através da seguinte equação: gasto energético total $=$ taxa metabólica basal × 1,1 (fator má absorção) × 1,5 a 1,7 (fator atividade) + 200 a $400 \mathrm{kcal} /$ dia. $^{(47)}$ Suplementos orais comerciais podem ser utilizados em casos selecionados. $^{(8)} 0$ acompanhamento desses pacientes pode ser feito pelo controle de ingestão de 3 dias ou inquérito recordatório de $24 \mathrm{~h}$, pela avaliação antropométrica (índice de massa corporal, circunferência do braço, circunferência muscular do braço, 
prega cutânea tricipital e percentual de perda de peso), pela análise da composição corporal (bioimpedância elétrica) e pela força muscular periférica (força do aperto de mão). A meta é manter o índice de massa corporal entre 20 a $25 \mathrm{~kg} / \mathrm{m}^{2}$, sendo que um índice menor que $19 \mathrm{~kg} / \mathrm{m}^{2}$ indica desnutrição significativa e necessidade de intervenção nutricional agressiva. Ainda, são componentes importantes da abordagem nutricional o tratamento da insuficiência pancreática exócrina e do diabete melito relacionado à $\mathrm{FC}^{\left({ }^{(47)}\right.}$

\section{Suplementação de oxigênio}

A doença pulmonar na FC tem caráter progressivo e, nas fases mais avançadas, se acompanha de hipoxemia e hipertensão pulmonar. ${ }^{(23)} 0$ tratamento da hipoxemia é importante para retardar a progressão da hipertensão pulmonar. Porém, os dados disponíveis sobre oxigenoterapia na FC são muito limitados. ${ }^{(8)}$ Assim, os critérios utilizados para oxigenoterapia contínua na FC são extrapolados dos estudos com doença pulmonar obstrutiva crônica: pressão arterial de oxigênio menor que $55 \mathrm{~mm} \mathrm{Hg}$, na vigília e em ar ambiente; ou pressão arterial de oxigênio menor que $59 \mathrm{~mm} \mathrm{Hg}$, na presença de edema de membros inferiores, policitemia ou evidência eletrocardiográfica/ecocardiográfica de aumento de câmaras direitas ou hipertensão pulmonar. Ainda, uma percentagem de pacientes com FC apresenta hipoxemia somente durante o exercício ou durante o sono. A oxigenoterapia durante o exercício está indicada se a saturação de oxigênio cair abaixo de 88 a 90\%. A oxigenoterapia noturna está indicada se a saturação de oxigênio for menor que 88 a $90 \%$ por $10 \%$ ou mais do tempo total de sono. ${ }^{(8)}$ Algumas situações específicas podem necessitar pressão positiva contínua nas vias aéreas durante o sono. A ventilação mecânica não-invasiva pode ser uma medida de suporte temporária para os pacientes com insuficiência respiratória crônica que aguardam transplante pulmonar. ${ }^{(24)}$

\section{Abordagem das manifestações extra-pulmonares}

Os pacientes com FC e fenótipo de insuficiência pancreática exócrina devem receber suplementação de enzimas pancreáticas nas refeições e lanches. A dose inicial de enzimas para o adulto é aproximadamente $500 \mathrm{U}$ de lípase $/ \mathrm{kg} /$ refeição e metade dessa dose nos lanches. As doses devem ser ajustadas de acordo com as necessidades clínicas até o máximo de $2.500 \mathrm{U}$ de lípase $/ \mathrm{kg} /$ refeição. Os pacientes com insuficência pancreática estão predispostos à má absorção das vitaminas lipossolúveis A, D, E e K. A suplementação dessas vitaminas é recomendada de rotina. ${ }^{(8)}$

Aproximadamente 20 a $25 \%$ dos pacientes com FC desenvolvem doença hepática, mas apenas 6 a 8\% deles evoluem para cirrose. Os testes de função hepática têm baixa sensibilidade e especificidade para o diagnóstico. Um sistema de escore ultra-sonográfico pode contribuir para a identificação da doença hepática crônica em adultos. Há evidências de benefício do ácido ursodeoxicólico na doença hepática relacionada com a FC. A dose apropriada é $20 \mathrm{mg} / \mathrm{kg} / \mathrm{dia}$ em duas tomadas. 0 transplante hepático tem sido uma estratégia terapêutica importante para os pacientes com doença hepática crônica avançada. ${ }^{(8)}$

A prevalência de diabete melito e de intolerância à glicose aumenta com a idade. 0 estado clínico e a função pulmonar deterioram-se nos anos precedentes ao diagnóstico do diabete e ocorre piora na sobrevida. 0 rastreamento regular com testes orais de tolerância à glicose permitem a intervenção precoce com insulina. ${ }^{(48,49)}$

A prevalência de osteoporose varia de 38 a 77\% em pacientes adultos. Os princípios para prevenir a doença óssea consistem em vigilância intensa, principalmente durante a puberdade, associada a exercício físico e suplementação com cálcio e vitaminas D e K. Os bifosfonados, por via oral ou intravenosa, são úteis para tratar doença estabelecida. ${ }^{(50)}$

Noventa e cinco por cento dos homens com FC são inférteis. A infertilidade decorre de anormalidades no trato reprodutivo, resultando em azoospermia obstrutiva. ${ }^{(51,52)} \mathrm{A}$ ausência de espermatozóides no espermograma confirma a infertilidade. Técnicas como aspiração microcirúrgica de esperma do epidídimo, aspiração percutânea de esperma do epidídimo e biópsia testicular, permitem obter espermatozóides. A técnica de concepção assistida de injeção intra-citoplasmática do espermatozóide no oócito permite a paternidade biológica desses pacientes. Porém, é um processo caro, disponível somente em grandes centros e com uma taxa de sucesso por ciclo de 12 a $45 \% .{ }^{(53)}$ 
Embora existam relatos sobre a redução na fertilidade feminina na FC, essa afirmativa tem sido questionada. A escolha do contraceptivo é difícil e exige que seja individualizada caso a caso. 0 uso da contracepção oral pode acarretar piora do diabete, da má absorção e da disfunção hepática. Por outro lado, o uso de antibióticos de largo espectro pode afetar a absorção e a eficácia dos contraceptivos orais. Os desfechos fetais e maternos da gestação na FC, em geral, são favoráveis. 0 risco da gestação está aumentado na doença pulmonar avançada $\left(\mathrm{VEF}_{1}<50 \%\right.$ do previsto), no diabete melito e na desnutrição, porém, o ponto de corte para a contra-indicação clínica da gestação não está estabelecido. ${ }^{(53)}$

\section{Transição da equipe pediátrica para a equipe de adultos}

0 processo de transição dos cuidados de saúde entre equipes que lidam com diferentes faixas etárias é uma estratégia importante a ser desenvolvida em todos os centros de FC. Além da vantagem da abordagem mais direcionada a problemas clínicos específicos da idade, o programa de adulto deve priorizar a independência e autonomia do indivíduo. Embora seja sugerido que a transição ocorra entre os 16 a 18 anos, deve haver flexibilidade, levando em consideração a maturidade e estado clínico do paciente. ${ }^{(54)} \mathrm{Em}$ geral, a transição requer estabilidade clínica da doença. Os pacientes com exacerbação grave, com doença terminal ou em lista de transplante não são candidatos à transição. ${ }^{(8)}$

\section{Transplante pulmonar}

0 transplante pulmonar está relacionado com a perspectiva de maior sobrevida e de maior qualidade de vida na doença pulmonar avançada. Em virtude da natureza supurativa da FC, existe a necessidade de pneumonectomia bilateral para evitar infecção no pulmão enxertado. A técnica mais utilizada é o transplante pulmonar duplo, através de procedimento cirúrgico seqüencial bilateral, com doador cadavérico. 0 transplante lobar de doador vivo é uma alternativa, em especial, para os pacientes que não podem aguardar na lista por um doador cadavérico e requer pequena estatura do receptor e proporcionalidade de volume com os órgãos a serem enxertados. ${ }^{(55)}$ Os critérios para referenciar o paciente incluem: $\mathrm{VEF}_{1}<30 \%$ do previsto; hipoxemia grave; hipercapnia; prejuízo funcional crescente ou aumento na duração e freqüência do tratamento hospitalar para exacerbações; complicações pulmonares ameaçadoras à vida como hemoptise; aumento da resistência dos patógenos bacterianos aos antibióticos. ${ }^{(56)} \mathrm{Em}$ virtude da maior sobrevida dos pacientes com FC, a utilização do $\mathrm{VEF}_{1}<30 \%$ do previsto tem sido revista como critério de referenciamento para transplante. ${ }^{(5)}$ A taxa de declínio da função pulmonar tem sido sugerida como um critério mais fidedigno. Um novo modelo para referenciamento e predição de mortalidade tem sido proposto, a partir da pontuação de múltiplas variáveis clínicas e funcionais. A sobrevida pós-transplante em 5 anos tem sido 50\%. ${ }^{(55)}$

\section{Avanços e perspectivas}

Recentemente, um estudo em pacientes com FC entre 2 a 18 anos de idade, sem colonização por $P$. aeruginosa, mostrou que a vacinação por uma vacina bivalente a partir do flagelo da $P$. aeruginosa foi eficiente em reduzir o risco de infecção por essa bactéria, podendo, assim, contribuir para a maior sobrevida desses pacientes. ${ }^{(57)}$

0 princípio da terapia gênica envolve a administração do RNA ou do DNA para as células epiteliais das vias aéreas a fim de compensar o defeito genético. As dificuldades técnicas incluem a necessidade de re-administrações contínuas devido ao turnover das células alvo. Além disso, a administração do material gênico nas vias aéreas precisa vencer as defesas sistêmicas e locais pulmonares. A utilização de vetores virais para essa administração tem maior eficiência de transdução, porém, não se tem encontrado solução para evitar a resposta imunológica que surge com as re-administrações. A utilização de vetores não-virais está associada com uma resposta imunológica bem menos intensa, porém, possui uma eficiência menor de transdução. Além disso, a baixa expressão da CFTR e o curso episódico da doença pulmonar tornam difícil a utilização dos desfechos convencionais como medida de eficácia da terapêutica gênica. Dessa forma, a terapia gênica não se converteu ainda em realidade clínica a despeito de inúmeros ensaios clínicos. ${ }^{(58,59)}$

Uma perspectiva de tratamento consiste na terapêutica com células-tronco. Várias populações celulares derivadas da medula óssea adulta ou do cordão umbilical podem localizar uma 
variedade de órgãos e adquirir características fenotípicas e funcionais de células orgânicas específicas maduras. Isso permitiria corrigir o defeito genético através da regeneração de células epiteliais respiratórias. ${ }^{(60)}$ Entretanto, o conhecimento das células-tronco pulmonares é muito escasso e a pesquisa está em fase muito inicial. ${ }^{(58,59)}$

\section{Conclusões}

A FC tornou-se também uma doença do adulto, exigindo o envolvimento do pneumologista e de outros especialistas de adultos para o seu tratamento. 0 tratamento padrão para a doença pulmonar inclui antibioticoterapia, higiene das vias aéreas, exercício, mucolíticos, broncodilatadores, oxigênio, agentes antiinflamatórios e suporte nutricional. A utilização adequada dessas medidas resulta em pacientes com FC sobrevivendo na vida adulta com melhor qualidade de vida.

\section{Referências}

1. Riordan JR, Rommens JM, Kerem B, Alon N, Rozmahel R, Grzelczak Z, et al. Identification of the cystic fibrosis gene: cloning and characterization of complementary DNA. Science. 1989;245(4922):1066-73. Erratum in: Science 1989;245(4925):1437.

2. Ackerman MJ, Clapham DE. Ion channels--basic science and clinical disease. N Engl J Med. 1997;336(22):1575-86. Erratum in: N Engl J Med. 1997;337(8):579.

3. Barasch J, al-Awqati Q. Defective acidification of the biosynthetic pathway in cystic fibrosis. J Cell Sci Suppl. 1993;17:229-33.

4. Rowe SM, Miller S, Sorscher EJ. Cystic fibrosis. N Engl J Med. 2005;352(19):1992-2001.

5. Rosenstein BJ. What is a cystic fibrosis diagnosis? Clin Chest Med. 1998;19(3):423-41, v. Review.

6. Santos $\mathrm{Cl}$, Ribeiro JD, Ribeiro AF, Hessel G. Análise crítica dos escores de avaliação de gravidade da fibrose cística: Estado da arte. J Bras Pneumol. 2007;30(3):286-98.

7. Andersen DH. Cystic fibrosis of the pancreas and its relation to celiac disease: a clinical and pathologic study. Am J Dis Child. 1938;56:344-99.

8. Yankaskas JR, Marshall BC, Sufian B, Simon RH, Rodman D. Cystic fibrosis adult care: consensus conference report. Chest. 2004;125(1 Suppl):1S-39S.

9. Rosenstein BJ, Cutting GR. The diagnosis of cystic fibrosis: a consensus statement. Cystic Fibrosis Foundation Consensus Panel. J Pediatr. 1998;132(4):589-95.

10. Karczeski B, Cutting G. Diagnosis of cystic fibrosis, CFTR-related disease and screening. Prog Respir Res. 2006;34:69-76.

11. Groman JD, Meyer ME, Wilmott RW, Zeitlin PL, Cutting GR. Variant cystic fibrosis phenotypes in the absence of CFTR mutations. N Engl J Med. 2002;347(6):401-7.

12. Groman JD, Karczeski B, Sheridan M, Robinson TE, Fallin MD, Cutting GR. Phenotypic and genetic characterization of patients with features of "nonclassic" forms of cystic fibrosis. J Pediatr. 2005;146(5):675-80.

13. Mekus F, Ballmann M, Bronsveld 1, Dörk T, Bijman J, Tümmler B, et al. Cystic-fibrosis-like disease unrelated to the cystic fibrosis transmembrane conductance regulator. Hum Genet. 1998;102(5):582-6.

14. Chmiel JF, Drumm ML, Konstan MW, Ferkol TW, Kercsmar CM. Pitfall in the use of genotype analysis as the sole diagnostic criterion for cystic fibrosis. Pediatrics. 1999;103(4 Pt 1):823-6.

15. Gilljam M, Ellis L, Corey M, Zielenski J, Durie P, Tullis DE. Clinical manifestations of cystic fibrosis among patients with diagnosis in adulthood. Chest. 2004;126(4):1215-24.

16. McWilliams TJ, Wilsher ML, Kolbe J. Cystic fibrosis diagnosed in adult patients. N Z Med J. 2000;113(1102):6-8.

17. Widerman E, Millner L, Sexauer W, Fiel S. Health status and sociodemographic characteristics of adults receiving a cystic fibrosis diagnosis after age 18 years. Chest. 2000;118(2):427-33.

18. Lemos AC, Matos E, Franco R, Santana P, Santana MA. Fibrose cística em adultos: aspectos clínicos e espirométricos. J Bras Pneumol. 2004;30(1):9-13.

19. Paschoal IA, de Oliveira Villalba W, Bertuzzo CS, Cerqueira EM, Pereira MC. Cystic fibrosis in adults. Lung. 2007;185(2):81-7.

20. Kerem E, Conway S, Elborn S, Heijerman H; Consensus Committee. Standards of care for patients with cystic fibrosis: a European consensus. J Cyst Fibros. 2005;4(1):7-26.

21. Ramsey BW. Management of pulmonary disease in patients with cystic fibrosis. N Engl J Med. 1996;335(3):179-88. Erratum in: N Engl J Med. 1996;335(15):1167.

22. Ratjen F, Döring G. Cystic fibrosis. Lancet. 2003; 361(9358):681-9.

23. Noone PG, Knowles MR. Standard therapy of cystic fibrosis lung disease. In: Yankaskas JR, Knowles MR, editors. Cystic fibrosis in adults. Philadelphia: Lippincott Williams \& Wilkins; 1999. p. 145-73.

24. Marshall BC, Samuelson WM. Basic therapies in cystic fibrosis. Does standard therapy work? Clin Chest Med. 1998;19(3):487-504, vi.

25. Gibson RL, Burns JL, Ramsey BW. Pathophysiology and management of pulmonary infections in cystic fibrosis. Am J Respir Crit Care Med. 2003;168(8):918-51.

26. Davies JC. Current and novel antimicrobial approaches. Prog Respir Res. 2006;34:180-6.

27. Wood RE, Leigh MW. What is a "pulmonary exacerbation" in cystic fibrosis? J Pediatr. 1987;111(6 Pt 1):841-2.

28. Kang SH, Piovesan DM, Hoffmann CF, Franciscatto E, Millán $\mathrm{T}$, Lacerda $\mathrm{C}$, et al. Características dos pacientes adolescentes e adultos com fibrose cística do Hospital de Clínicas de Porto Alegre. Revista AMRIGS. 2004;48(3):162-70.

29. Conway S, Denton M. Staphylococcus aureus and MRSA. Prog Respir Res. 2006;34:153-9.

30. Kahl B, Herrmann M, Everding AS, Koch HG, Becker K, Harms $\mathrm{E}$, et al. Persistent infection with small colony variant strains of Staphylococcus aureus in patients with cystic fibrosis. J Infect Dis. 1998;177(4):1023-9.

31. Weaver LT, Green MR, Nicholson K, Mills J, Heeley ME, Kuzemko JA, et al. Prognosis in cystic fibrosis treated with continuous flucloxacillin from the neonatal period. Arch Dis Child. 1994;70(2):84-9.

32. Ratjen F, Comes G, Paul K, Posselt HG, Wagner TO, Harms $\mathrm{K}$, et al. Effect of continuous antistaphylococcal therapy on 
the rate of $\mathrm{P}$. aeruginosa acquisition in patients with cystic fibrosis. Pediatr Pulmonol. 2001;31(1):13-6.

33. Smyth A, Walters S. Prophylactic antibiotics for cystic fibrosis. Cochrane Database Syst Rev. 2003;(3):CD001912.

34. Emerson J, Rosenfeld M, McNamara S, Ramsey B, Gibson RL. Pseudomonas aeruginosa and other predictors of mortality and morbidity in young children with cystic fibrosis. Pediatr Pulmonol. 2002;34(2):91-100.

35. Burns JL, Gibson RL, McNamara S, Yim D, Emerson J, Rosenfeld M, et al. Longitudinal assessment of Pseudomonas aeruginosa in young children with cystic fibrosis. J Infect Dis. 2001;183(3):444-52.

36. Armstrong D. Pseudomonas aeruginosa: clinical research. Prog Respir Res. 2006;34:131-7.

37. Orenstein DM. Cystic fibrosis. Philadelphia: Lippincott Williams \& Wilkins; 2000.

38. Gibson RL, Emerson J, McNamara S, Burns JL, Rosenfeld M, Yunker A, et al. Significant microbiological effect of inhaled tobramycin in young children with cystic fibrosis. Am J Respir Crit Care Med. 2003;167(6):841-9.

39. Döring G, Conway SP, Heijerman HG, Hodson ME, Høiby $\mathrm{N}$, Smyth A, et al. Antibiotic therapy against Pseudomonas aeruginosa in cystic fibrosis: a European consensus. Eur Respir J. 2000;16(4):749-67.

40. McArdle JR, Talwalkar JS. Macrolides in cystic fibrosis. Clin Chest Med. 2007;28(2):347-60.

41. Ziegler B, Rovedder PME, Lukrafka JL, Oliveira CL, MennaBarreto SS, Dalcin PTR. Capacidade submáxima de exercício em pacientes adolescentes e adultos com fibrose cística. J Bras Pneumol. 2007;33(3):263-9.

42. Wark PA, McDonald V, Jones AP. Nebulised hypertonic saline for cystic fibrosis. Cochrane Database Syst Rev. 2005;(3):CD001506.

43. Elkins MR, Robinson M, Rose BR, Harbour C, Moriarty CP, Marks GB, et al. A controlled trial of long-term inhaled hypertonic saline in patients with cystic fibrosis. $\mathrm{N}$ Engl $\mathrm{J}$ Med. 2006;354(3):229-40.

44. Hilliard T, Balfour-Lynn 1. Anti-Inflammatory Agents. Prog Respir Res. 2006;34:187-94.

45. Dezateux C, Walters S, Balfour-Lynn 1. Inhaled corticosteroids for cystic fibrosis. Cochrane Database Syst Rev. 2000;(2):CD001915.

46. Dezateux C, Crighton A. Oral non-steroidal anti-inflammatory drug therapy for cystic fibrosis. Cochrane Database Syst Rev. 2000;(2):CD001505.
47. Kalnins D, Stewart C, Tullis E, Pencharz PB. Nutrition. In: Yankaskas JR, Knowles MR, editors. Cystic fibrosis in adults. Philadelphia: Lippincott-Raven Publishers; 1999. p. 289-307.

48. Alves CA, Aguiar RA, Alves AC, Santana MA. Diabetes melito: uma importante co-morbidade da fibrose cística. J Bras Pneumol. 2007;33(2):213-21.

49. Bridges N, Spowart K. Diabetes in Cystic Fibrosis. Prog Respir Res. 2006;34:278-83.

50. Elkin S. Arthritis, vasculitis and bone disease. Prog Respir Res. 2006;34:270-7.

51. Taussig LM, Lobeck CC, di Sant'Agnese PA, Ackerman DR, Kattwinkel J. Fertility in males with cystic fibrosis. N Engl J Med. 1972 Sep 21;287(12):586-9.

52. Barreto C, Pinto LM, Duarte A, Lavinha J, Ramsay M. A fertile male with cystic fibrosis: molecular genetic analysis. J Med Genet. 1991;28(6):420-1.

53. Sueblinvong V, Whittaker LA. Fertility and pregnancy: common concerns of the aging cystic fibrosis population. Clin Chest Med. 2007;28(2):433-43.

54. Yankaskas JR, Fernald GW. Adult social issues. In: Yankaskas JR, Knowles MR, editors. Cystic fibrosis in adults. Philadelphia: Lippincott-Raven Publishers; 1999. p. 465-76.

55. Goldberg HJ, Deykin A. Advances in lung transplantation for patients who have cystic fibrosis. Clin Chest Med. 2007;28(2):445-57.

56. Yankaskas JR, Mallory GB Jr. Lung transplantation in cystic fibrosis: consensus conference statement. Chest. 1998;113(1):217-26.

57. Döring G, Meisner C, Stern M; for the Flagella Vaccine Trial Study Group. A double-blind randomized placebocontrolled phase III study of a Pseudomonas aeruginosa flagella vaccine in cystic fibrosis patients. Proc Natl Acad Sci U S A. 2007;104(26):11020-5.

58. Sueblinvong V, Suratt BT, Weiss DJ. Novel therapies for the treatment of cystic fibrosis: new developments in gene and stem cell therapy. Clin Chest Med. 2007;28(2):361-79.

59. Boyd A. Gene and stem cell therapy. Prog Respir Res. 2006;34:221-9.

60. Wang $\mathrm{X}$, Willenbring $\mathrm{H}$, Akkari $\mathrm{Y}$, Torimaru $\mathrm{Y}$, Foster $M$, Al-Dhalimy $M$, et al. Cell fusion is the principal source of bone-marrow-derived hepatocytes. Nature. 2003;422(6934):897-901. 